\title{
Differential expression of proteases in human gestational tissues before, during and after spontaneous-onset labour at term
}

\author{
D. Tsatas ${ }^{1,3 *}$, M. S. Baker ${ }^{2,3}$ and G. E. Rice ${ }^{1,3}$ \\ ${ }^{1}$ Department of Perinatal Medicine, Perinatal Research Centre, Royal Women's Hospital, Carlton, Victoria, 3053, Australia; \\ ${ }^{2}$ Gynaecological Cancer Research Centre, Royal Women's Hospital, Carlton, Victoria, 3053, Australia; and ${ }^{3}$ Department of Obstetrics and \\ Gynaecology, University of Melbourne, Parkville, Victoria, 3052, Australia
}

\begin{abstract}
A number of tightly regulated proteolytic enzyme systems, including the plasminogen activation cascade and matrix metalloproteases, play integral roles in the remodelling of extracellular matrices during pregnancy and parturition. This study assessed these labour-associated changes in protease activity in human gestational tissues. Amnion, choriodecidua and placenta collected from women before (at caesarean section, not in labour), during (at caesarean section, in labour) and after (spontaneous-onset labour, normal vaginal delivery) labour were examined on gelatin-substrate SDS-PAGE zymography. All tissues displayed major $55 \mathrm{kDa}$ plasminogen-dependent activity that was abolished by the serine protease inhibitors $(10 \mathrm{mmol}$ phenylmethylsulphonylfluoride $1^{-1}, 100 \mathrm{mmol}$ epsilon aminocaproic acid $\mathrm{l}^{-1}, 1 \mathrm{mmol}$ Glu-Gly-Arg chloromethylketone $\mathrm{l}^{-1}$ ). The enzymic activity was identified as urokinase plasminogen activator on the basis of its co-migration with reference standard and western blot analysis, and did not vary with labour status. An additional protease with an apparent molecular mass of approximately $90 \mathrm{kDa}$ was detected in all tissues. Densitometric measurement of these tissues showed a significant $(P<0.05)$ increase in this enzyme activity with labour onset. Heavy metal chelators ( $1 \mathrm{mmol} 1,10$ phenanthroline $\mathrm{l}^{-1}$ and $10 \mathrm{mmol}_{\text {EDTA }}^{-1}$ ) selectively blocked the $90 \mathrm{kDa}$ activity, consistent with the proposal that it is a metalloprotease. Co-migration with reference standard and western blot analysis confirmed the identity of this protease as the matrix metalloprotease 9 (MMP9). Immunoreactive MMP-9 protein was also significantly $(P<0.05)$ increased during and after labour compared with before labour in all tissues examined. It is proposed that the upregulated expression of MMP-9 is involved in fetal membrane rupture and placental separation during and after labour onset, respectively. In conclusion, the regulated repertoire of protease activities expressed by human gestational tissues implies an important role for matrix-degrading enzymes during human parturition.
\end{abstract}

\section{Introduction}

Processes that involve extensive extracellular matrix remodelling are intrinsic to successful parturition. Examples of such processes include cervical ripening before delivery, fetal membrane rupture and placental separation from maternal tissues (Rajabi et al., 1988; Jeffrey, 1991; Granstrom et al., 1992; Vadillo-Ortega et al., 1995). These labourassociated changes depend on the concerted actions of several proteolytic enzyme systems, one of which is the plasminogen activation cascade. This system converts the abundant circulating pro-enzyme plasminogen to the active serine protease plasmin that is capable of degrading most extracellular matrix proteins either directly or indirectly via the activation of latent collagenases (Emonard and Grimaud, 1990; Conese and Blasi, 1995; Ries and Petrides, 1995). The

Revised manuscript received 26 October 1998. generation of plasmin is dependent upon the availability and activity of urokinase plasminogen activator (uPA) (Vassalli et al., 1991; Plow et al., 1995).

Another important class of mediators of tissue remodelling that has been investigated in human pregnancy and parturition includes the matrix metalloproteases, particularly matrix metalloprotease 2 (MMP-2) and matrix metalloprotease 9 (MMP-9) (Shimonovitz et al., 1994; BryantGreenwood and Yamamoto, 1995; Vadillo-Ortega et al., 1995). These enzymes degrade the major components of basement membranes, collagen type IV, laminin and fibronectin. The enzymes are secreted in a latent form and may be activated by a variety of enzymes, such as plasmin and trypsin. Matrix metalloproteases require intrinsic $\mathrm{Zn}^{2+}$ and extrinsic $\mathrm{Ca}^{2+}$ for full catalytic activity and are regulated by their physiological inhibitors, tissue inhibitors of metalloproteases (TIMPs) (Emonard and Grimaud, 1990; Woessner, 1991; Ries and Petrides, 1995; Salamonsen, 1996). Collectively, the 
plasminogen activation cascade and the family of matrix metalloproteases have the potential to degrade all components of the extracellular matrix, rendering these enzymes likely candidates for critical peripartal remodelling events.

Although the mechanisms that trigger the onset of labour remain largely unknown, available evidence indicates that enzymic, in addition to mechanical influences, play a significant role. Consistent with this proposal, serum collagenase concentrations increase during cervical ripening at term (Granstrom et al., 1992). In addition, comparative evaluation studies of biomechanical properties of human fetal membranes obtained before and after delivery demonstrate a decrease in total collagen content in the amnion as the rupture site is approached (Ibrahim et al., 1983). These observations support the contention that localized degenerative changes in amnion and chorionic tissue, partially mediated by collagenolytic activity, may be sufficient to reduce tensile strength and hence mediate fetal membrane rupture at term. In contrast, the biochemical evidence supporting a role for uPA during late pregnancy and at labour is limited. The aim of the present study was to characterize spatial differences in matrix-degrading enzyme activity in tissues obtained from women before, during and after spontaneous-onset labour, and to establish whether labour-associated changes occur in these proteolytic activities.

\section{Materials and Methods}

\section{Tissue collection}

Amnion, choriodecidua and placenta were collected at 37-40 weeks of gestation from women in three groups: (i) before labour $(n=7)$ from women not in labour, undergoing elective caesarean section for breech presentation, cephalopelvic disproportion or previous caesarean section; (ii) during labour $(n=8)$ from women in spontaneous onset labour (cervical dilatation $>4 \mathrm{~cm}$ ) undergoing caesarean section for fetal distress and obstructed labour; and (iii) after labour $(n=6)$ from women with spontaneous-onset labour and normal vaginal delivery.

The possibility of regional variation in protease expression was eliminated by extracting proteins from different anatomical sites of placenta and fetal membranes at term. Placental tissue was collected from three topographical locations: the placental edge, halfway between the placental edge and umbilical cord insertion, and from a point central to the placenta. Reflected fetal membranes were collected from regions proximal, middle and distal to the placenta. Amnion lying directly over the placenta was also tested. Zymographic analyses failed to show any significant $(P>0.05)$ site variability in net proteolytic activity in amnion, choriodecidua or placenta and hence further analyses were performed on specimens that were randomly sampled from gestational tissues.

Tissues were snap frozen in liquid nitrogen and stored at $-80^{\circ} \mathrm{C}$ until processed. Informed consent was obtained from all patients and the study was approved by the Research and
Ethical Committees of the Royal Women's Hospital, Melbourne, Australia.

\section{Gelatin zymography}

Assessment of gelatin-degrading enzymes in human term gestational tissues was performed by electrophoretic zymography, as previously described (Heussen and Dowdle, 1980). Briefly, $1 \mathrm{~g}$ tissue was homogenized in $3 \mathrm{ml}$ PBS and centrifuged $(1000 \mathrm{~g}$ for $20 \mathrm{~s}$ ) to remove insoluble material. The protein content in the recovered supernatant was determined by the Bio-Rad protein assay (Bio-Rad, Munich) using BSA (ICN Biochemicals, Cleveland, $\mathrm{OH}$ ) as the standard. Tissue samples were adjusted to a final concentration of $1 \mu \mathrm{g}$ protein per microlitre sample buffer $(2.5 \%(\mathrm{w} / \mathrm{v})$ SDS, $1 \%(\mathrm{w} / \mathrm{v})$ sucrose, $4 \mu \mathrm{g}$ bromophenol blue $\left.\mathrm{ml}^{-1}\right)$. Samples $(10 \mu \mathrm{g}$ per well) were subjected to electrophoresis at $4^{\circ} \mathrm{C}$ on $10 \%(\mathrm{v} / \mathrm{v})$ SDS-polyacrylamide gels containing $1 \mathrm{mg}$ gelatin $\mathrm{ml}^{-1}$ (ICN Biochemicals, Cleveland, $\mathrm{OH}$ ) and $1.2 \mathrm{mg}$ human plasminogen $\mathrm{ml}^{-1}$ (American Diagnostica, Greenwich, CT) for $4 \mathrm{~h}$ at a constant current of $8 \mathrm{~mA}$. The enzyme activity in the polyacrylamide gels was restored by removal of SDS by gentle shaking at room temperature in $2.5 \%(\mathrm{v} / \mathrm{v})$ Triton-X100 (BDH Chemicals, Victoria) for $30 \mathrm{~min}$. After incubation at room temperature for $16 \mathrm{~h}$ in PBS containing $0.9 \mathrm{mmol} \mathrm{CaCl}_{2} \mathrm{I}^{-1}$ and $1 \mathrm{mmol}$ $\mathrm{MgCl}_{2} \mathrm{l}^{-1}$, substrate gels were stained in $0.25 \%(\mathrm{w} / \mathrm{v})$ Coomassie Brilliant Blue (Bio-Rad, Munich) in methanol:acetic acid:water (50:10:50) and the stain was removed in the same solution without dye. Proteolytic activity was visualized as clear zones of lysis on a blue background of undigested gelatin. The molecular mass of the enzymes was estimated by comparison with protein standards (Bio-Rad, Munich) run in parallel on all gels.

The following protease inhibitors were added to the buffer in which the gels were incubated to characterize the types of protease involved in gelatin degradation: (i) serine protease inhibitors: $100 \mathrm{mmol}$ epsilon aminocaproic acid $\mathrm{l}^{-1}$ (Sigma Chemicals, St Louis, MO), and $10 \mathrm{mmol}$ phenylmethylsulphonylfluoride (PMSF) $\mathrm{l}^{-1}$ (ICN Biochemicals, Cleveland, $\mathrm{OH})$; (ii) metalloprotease inhibitors: $1 \mathrm{mmol} 1,10$ phenanthroline $1^{-1}$ (Sigma Chemicals, St Louis, MO), and

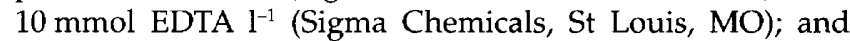
(iii) urokinase plasminogen activator: $1 \mathrm{mmol}$ Glu-Gly-Arg chloromethylketone $1^{-1}$ (Calbiochem, San Diego, CA). Quantitative analysis of gelatinolytic activity was performed by laser densitometry using a commercially available software package (ImageQuant Version 3.3, Molecular Dynamics).

\section{Western blot analyses}

The partial identity of the gelatin-degrading enzymes in human term gestational tissues was confirmed by western blot analyses. Briefly, gestational tissues were processed as described for electrophoretic zymography. Tissue samples (50 $\mu \mathrm{g}$ per lane) were size fractionated on a $10 \%(\mathrm{v} / \mathrm{v})$ SDSpolyacrylamide gel under non-reducing conditions and 


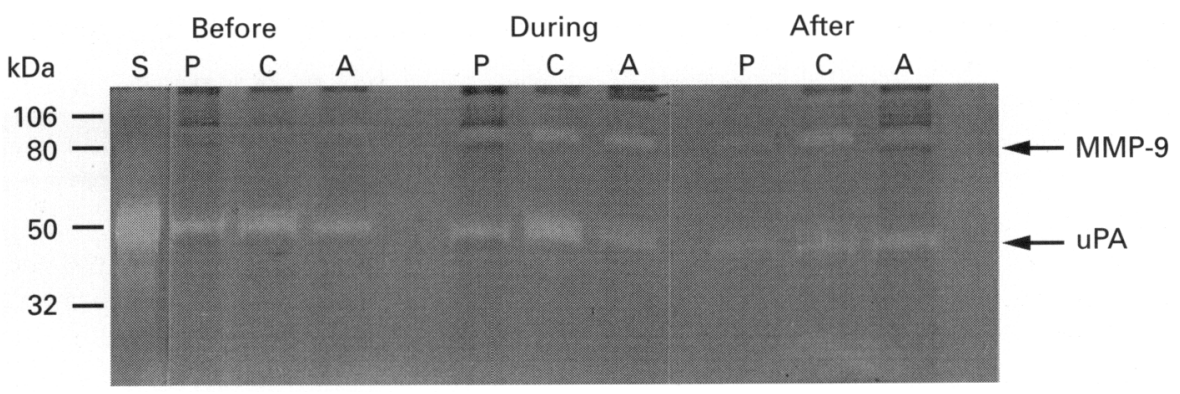

Fig. 1. Representative gelatin-substrate SDS-PAGE analysis of human gestational tissue supernatants with labour onset. Tissue extracts of placenta (P), choriodecidua (C) and amnion (A) obtained from women before, during and after spontaneous-onset labour at term displayed two major protease activities: UPA migrating at $55 \mathrm{kDa}$ and MMP-9 at approximately $90 \mathrm{kDa}$. Molecular mass markers and uPA standard (S) are shown on the left.

transferred to a nitrocellulose membrane (Schleicher and Scheull, Dassell) using a Semi-Phor semi-dry transfer unit (Hoefer Scientific Instruments, San Francisco, CA). Nonspecific binding sites were blocked by incubating transfers in blocking buffer $(5 \%(\mathrm{w} / \mathrm{v})$ non-fat dried milk, $50 \mathrm{mmol}$ Tris- $\left.\mathrm{HCl} \mathrm{l}^{-1}, 150 \mathrm{mmol} \mathrm{NaCl} \mathrm{l}^{-1}\right)$ at room temperature for $1 \mathrm{~h}$. The membranes were then incubated overnight at $4^{\circ} \mathrm{C}$ in blocking buffer containing either a polyclonal goat primary antibody against human uPA $\left(50 \mathrm{mg} \mathrm{ml}^{-1}\right.$; American Diagnostica, Greenwich, CT) or a monoclonal antibody against human MMP-9 (10 mg ml-1; University of Alabama at Birmingham, Birmingham, AL). The membranes were washed in $0.02 \%(\mathrm{v} / \mathrm{v})$ Tween-20 and PBS and incubated with a horseradish peroxidase-conjugated secondary antibody in blocking buffer at room temperature for $1 \mathrm{~h}$. After appropriate washing, protein bands were detected by enhanced chemiluminescence (Amersham Life Sciences, Arlington Heights, IL) and subsequent autoradiography.

\section{MMP-9 sandwich ELISA}

The presence and concentration of MMP-9 in human gestational tissues was determined using a commercially available sandwich ELISA kit (R\&D Systems, Minneapolis, $\mathrm{MN}$ ). The assay procedure involved the addition of $100 \mu \mathrm{l}$ buffered protein base with preservative provided by the supplier and $100 \mu 1$ MMP-9 standard, diluted test sample (all samples diluted 1:60 in assay diluent provided by the manufacturer) or blank. Plates were incubated for $2 \mathrm{~h}$ at room temperature with gentle agitation. The plates were then washed and $200 \mu \mathrm{l}$ detection antibody (polyclonal antibody against MMP-9 conjugated to horseradish peroxidase) was added to each well and incubated for $1 \mathrm{~h}$ at room temperature. Plates were washed and a $200 \mu \mathrm{l}$ volume of the substrate tetramethylbenzidine (TMB) was added to each well and incubated for $30 \mathrm{~min}$ at room temperature. The reaction of TMB with the horseradish peroxidase complex was terminated by the addition of $50 \mu \mathrm{l}$ of $2 \mathrm{~mol}$ sulfuric acid $\mathrm{l}^{-1}$. The absorbance was determined at $450 \mathrm{~nm}$ using a microplate reader (Model 3350; Bio-Rad Laboratories, Richmond, CA). A standard curve was generated using the
MMP-9 standard provided by the manufacturer (20.0-0.3 ng $\mathrm{ml}^{-1}$ ). The sensitivity of the assay was $0.16 \mathrm{ng} \mathrm{m}^{-1}$ sample and detected total MMP-9 immunoreactive protein in tissue extracts (that is, both pro- and active forms with equal efficiency).

\section{Statistical analyses}

Extracts were loaded such that all labour states and corresponding tissue type were represented on each gel to assess the variation in protease activities in human gestational tissues during labour. Homogeneity of variance was assessed by Bartlett's tests, and the data were subjected to ANOVA in which the variance was partitioned between tissue type and labour status. All analyses were performed using a commercially available statistics package (Statgraphics; STSC, MD). Statistical significance was indicated by $P<0.05$. Data are presented as means \pm SEM.

\section{Results}

\section{Zymographic analysis of protease expression}

Gelatin-substrate gels co-polymerized with plasminogen were used to characterize serine and metalloprotease matrixdegrading enzymic activity in human gestational tissues obtained from women before, during and after spontaneousonset labour at term. Compared with molecular mass markers, tissue extracts prepared from amnion, choriodecidua and placenta produced a number of lysis bands ranging from approximately 55 to $100 \mathrm{kDa}$ in size. A major $55 \mathrm{kDa}$ plasminogen-dependent activity that did not change significantly $(P>0.05)$ with labour states was detected in all tissue samples (Fig. 1). This enzymic activity was identified as uPA on the basis of its co-migration with a reference standard.

All tissue samples displayed a plasminogen-independent activity with apparent molecular mass of approximately $90 \mathrm{kDa}$ (Fig. 1). Densitometric absorbance values (arbitrary units) before, during and after labour in placenta (22.6 \pm 8.1 , 


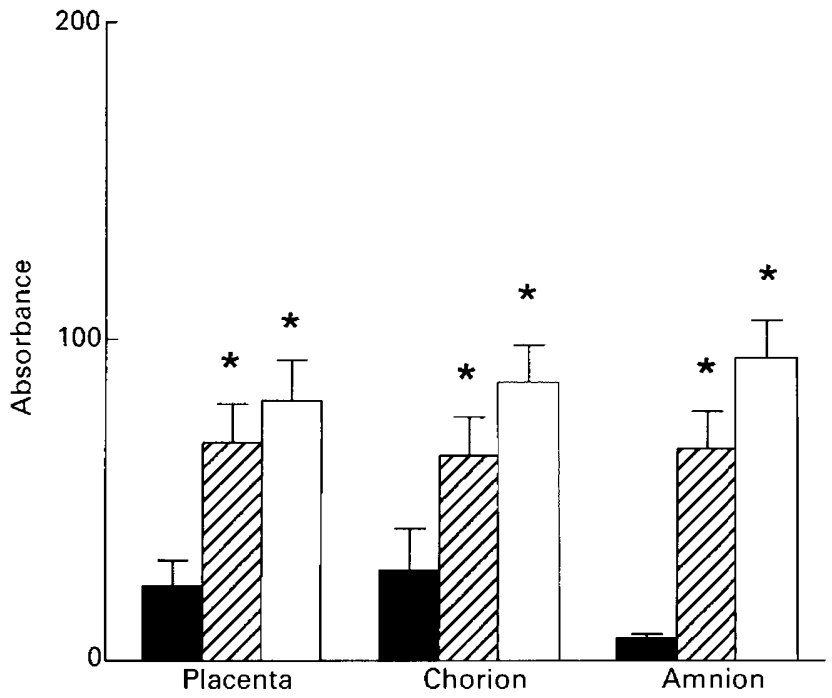

Fig. 2. Densitometric analysis of MMP-9 proteolytic activity in human gestational tissues. Multifactorial ANOVA revealed a significant $(P<0.05)$ increase in placenta, choriodecidua and amnion tissue during $(\triangle, n=8)$ and after $(\square, n=6)$ labour compared with before $(\boldsymbol{\square}, n=7)$ labour. All data are presented as mean \pm SEM; ${ }^{*} P<0.05$.

$67.4 \pm 12.2,80.8 \pm 12.9)$, choriodecidua $(27.7 \pm 13.0,63.6 \pm$ $12.2,86.9 \pm 11.7)$ and amnion $(7.1 \pm 1.4,65.9 \pm 11.9,94.8 \pm 11.9)$ showed a significant $(P<0.05)$ increase in this activity that corresponded to labour onset (Fig. 2).

\section{Inhibition of proteolytic activity in gestational tissue}

Incubation of zymograms in the presence of $1 \mathrm{mmol}$ Glu-Gly-Arg chloromethylketone $1^{-1}$, which inhibits uPA specifically, resulted in complete loss of the $55 \mathrm{kDa}$ lysis band (Fig. 3a). Similar results were obtained with serine protease

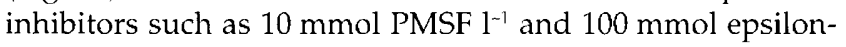
aminocaproic acid $\mathrm{l}^{-1}$ (data not shown). The $90 \mathrm{kDa}$ proteolytic band observed in human gestational tissues was completely inhibited when gels were incubated in the presence of the heavy metal chelators $1 \mathrm{mmol} 1,10$

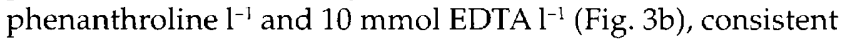
with the proposal that it is a matrix metalloprotease. On the basis of molecular mass and selective inhibition, the lysis band was identified as MMP-9.

\section{Western blot analysis of gestational tissue proteins}

Western blot analysis of amnion, choriodecidual and placental extracts using either a polyclonal antibody raised against human UPA or a monoclonal antibody against human MMP-9 is shown (Fig. 4). A single band corresponding to uPA with an apparent molecular mass of $55 \mathrm{kDa}$ was detected in all gestational tissues examined. Western blot experiments using a monoclonal antibody against human MMP-9 revealed the presence of two bands at approximately 180 and $90 \mathrm{kDa}$, the former representing the
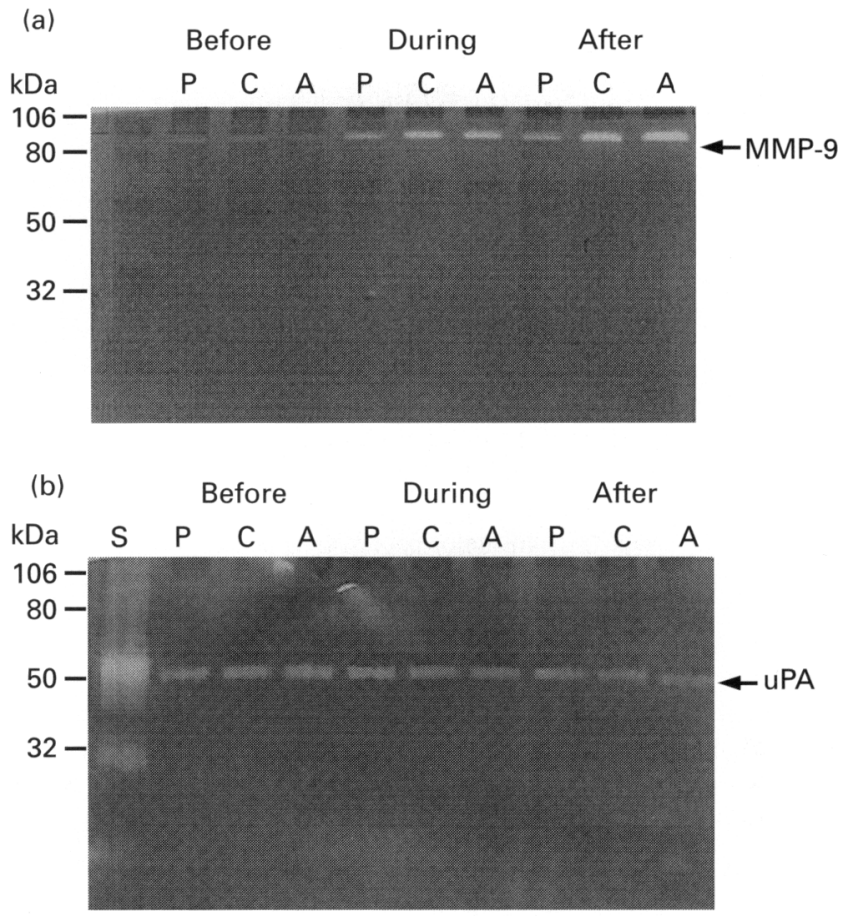

Fig. 3. Inhibition of human gestational tissue proteolytic activity. (a) Effect of $1 \mathrm{mmol}$ Glu-Gly-Arg chloromethylketone $1^{-1}$ on uPA activity expressed by placenta (P), choriodecidua (C) and amnion (A) tissue before, during and after spontaneous-onset labour at term. (b) Inhibition of MMP-9 proteolytic activity in gestational tissue by 1 mmol 1,10 phenanthroline $\mathrm{l}^{-1}$. Molecular mass markers and uPA standard (S) are shown on the left.

dimeric form of the protein. Some lower molecular mass bands were also detected, which most likely represent autodegradation of the enzyme.

\section{Immunoreactive MMP-9 in human gestational tissues}

The immunoreactive content of MMP-9 in human term gestational tissues before, during and after spontaneousonset labour was measured by ELISA. A statistically significant $(P<0.05)$ increase in total immunoreactive MMP9 protein was observed in placenta, choriodecidua and amnion tissue during and after labour when compared with the before labour group of patients (Fig. 5). Immunoreactive MMP-9 protein was not significantly different between the groups of patients tested during and after labour $(P>0.05)$.

\section{Discussion}

In this study, it is demonstrated by gelatin-zymography that uPA and MMP-9 proteolytic activity is present in human amnion, choriodecidua and placental extracts. MMP-9 activity increased significantly in these tissues during and after spontaneous-onset labour at term. In contrast, no labourassociated changes were detected in uPA activity. These data are consistent with reports that describe the induction of 
(a)

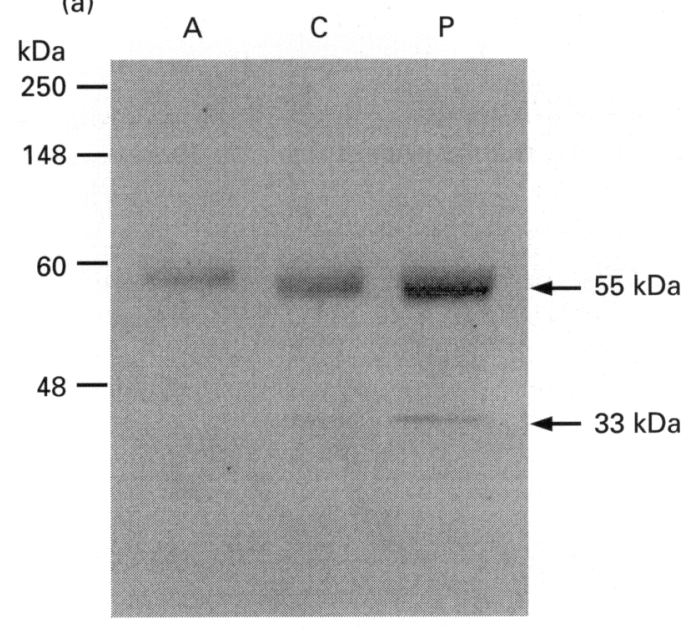

(b)

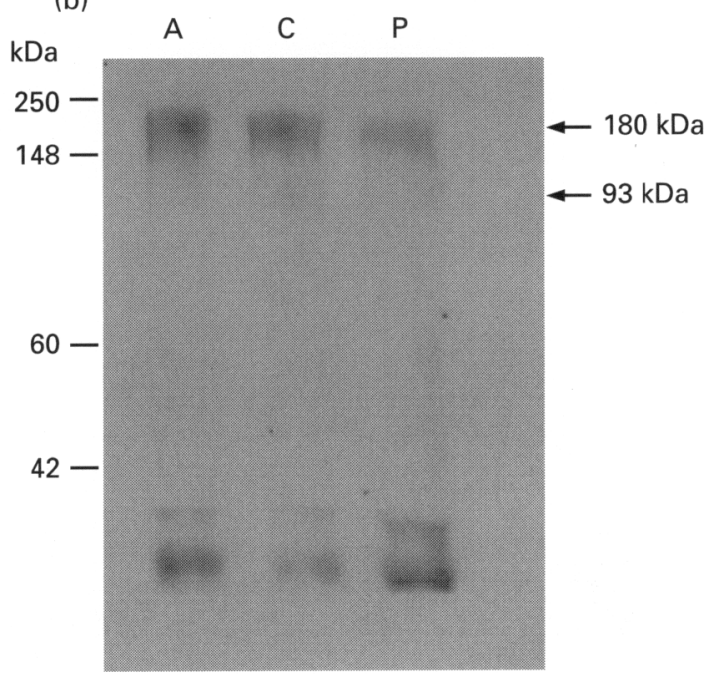

Fig. 4. Western blot analyses of human gestational tissue extracts. Protein extracts ( $50 \mu \mathrm{g}$ per lane) of placenta (P), choriodecidua (C) and amnion (A) were subjected to SDS-PAGE under non-reducing conditions and probed with either (a) a goat anti-human uPA antibody or (b) a monoclonal MMP-9 antibody.

MMP-9 activity in both human and rat amniochorionic membranes at term (Lei et al., 1995; Vadillo-Ortega et al., 1995). Furthermore, this study is the first to show an increase in this enzyme activity in human placental tissue with labour.

The upregulated expression of collagenolytic activity in intrauterine tissues with labour appears to be the result of increased synthesis of the enzyme. Northern and western blot analyses that show a significant increase in MMP-9 mRNA and protein, respectively, in fetal membranes from patients during labour compared with those not in labour support this proposal (Bryant-Greenwood and Yamamoto, 1995; Vadillo-Ortega et al., 1995). The data obtained in the present study also demonstrate a significant increase in gestational tissue MMP-9 immunoreactive protein with labour. Total immunoreactive MMP-9 content was two- to fourfold greater during and after labour compared with before labour in all tissues examined. This indicates that induction of MMP-9 during parturition is controlled largely at the genetic level, although other mechanisms such as differential activation of latent enzyme or reduction in TIMP expression cannot be excluded.

Although these data do not demonstrate a concomitant increase in UPA activity with labour, recent reports have documented that from a physiological point of view, uPA functions primarily via the occupancy of its specific cellular receptor, uPAR (Ellis and Dano, 1991; Blasi, 1993; Schmitt et al., 1995). In the present study, the net proteolytic activity in gestational tissue homogenates was examined and thus there was no distinction between cell-surface bound and soluble uPA. Consequently, zymographic analyses of uPA activity may not reflect the expression of the plasminogen activation cascade at the functionally significant cellular loci, that is, the cell surface. Tsatas et al. (1998) investigated, by northern blot analysis, the gene expression of uPA and its receptor in human gestational tissues obtained from women at different labour states. Consistent with the present study, it was reported that gestational tissue uPA gene expression was not altered by labour onset. In contrast, uPAR gene expression was significantly increased in amnion tissue during and after spontaneous-onset labour. These results emphasize that extracellular matrix turnover during pregnancy and parturition may be regulated by tissue concentrations of uPAR rather than uPA. Induction of UPAR in gestational tissues may promote increased binding of cell surface uPA, which subsequently results in increased proteolysis and thus contributes to labour-associated events such as the terminal remodelling of fetal membranes.

It is proposed that during fetal membrane rupture, uPA binds to UPAR on amnion epithelium and chorionic trophoblasts in both a paracrine and autocrine manner. Cell surface receptor-bound uPA initiates proteolysis by activating plasminogen that is either bound to the amniochorion or extracellular matrix. The generation of plasmin may subsequently activate latent metalloproteases, which contribute further to the degenerative changes observed in ruptured fetal membranes. By the same mechanism, co-ordinate expression of uPA, metalloproteases and UPAR by placental extravillous trophoblasts may facilitate placental separation from maternal tissues at labour. Consistent with this model, immunoreactive uPA and MMP-9 have been localized to amnion epithelium and trophoblasts of the chorion and placenta at term (Watanabe et al., 1993; Vadillo-Ortega et al., 1995; Tsatas et al., 1997). In addition, immunolocalization studies showed that chorionic and extravillous trophoblasts express uPAR and therefore have the potential to mediate cell surface proteolysis (Tsatas et al., 1997). The ability of plasminogen to bind to human amniochorionic membranes (Burgos et al., 1982; Jenkins et al., 1983 ) and the presence of immunoreactive plasminogen in these tissues (Watanabe et al., 1993) also supports this model.

In summary, the data obtained in this study clearly 
(a)

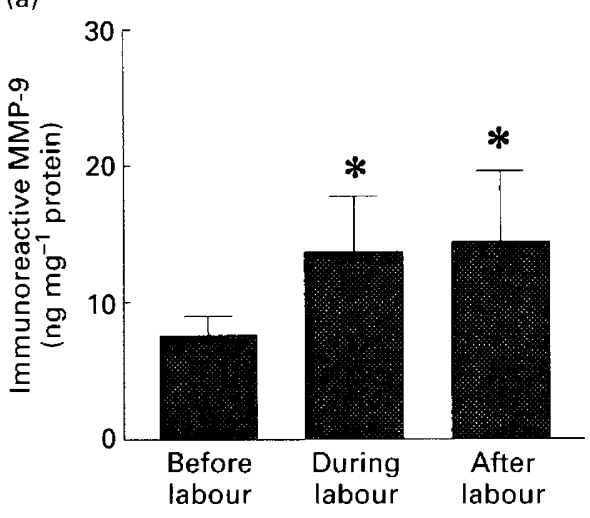

(b)

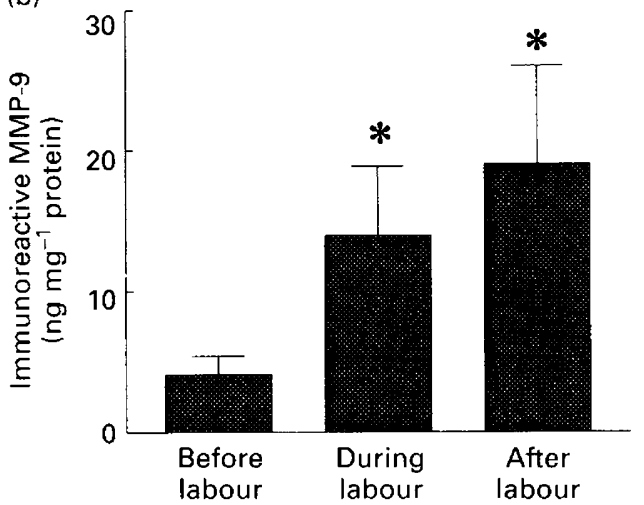

(c)

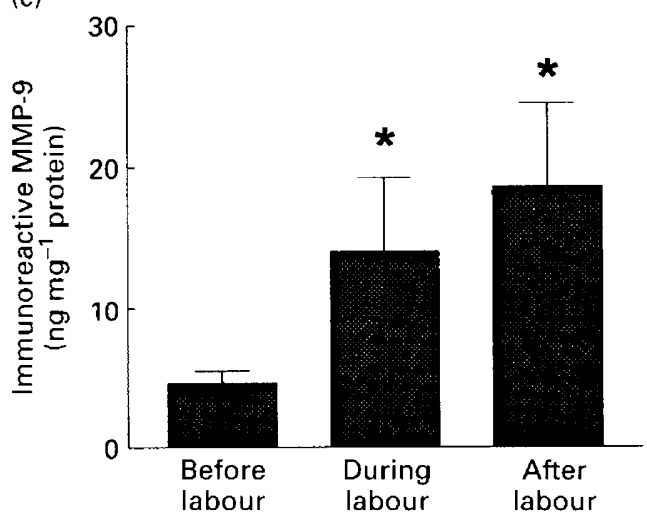

Fig. 5. Immunoreactive MMP-9 content in human term gestational tissues with labour onset. Immunoreactive MMP-9 content (ng mg ${ }^{-1}$ protein) as measured by ELISA in (a) placenta, (b) choriodecidua and (c) amnion tissue before $(n=7)$, during $(n=7)$ and after $(n=7)$ labour onset. One-way ANOVA revealed a significant $(P<0.05)$ increase in immunoreactive MMP-9 during and after labour compared with before labour in all tissues examined. Data are presented as mean \pm SEM; (a) $P=0.01$, (b) $P=0.0001$, (c) $P=0.006$.

establish a labour-associated increase in both MMP-9 enzymic activity and immunoreactive protein in human term gestational tissues. In addition, this is the first study to examine the activity of uPA in human term placenta, choriodecidua and amnion tissue with labour. Although uPA was present in all tissues at term, no labour-associated change was identified. The temporal increase in MMP-9 activity and the presence of uPA in human fetal membranes and placenta strongly implies that these proteases have a causal role in the degenerative changes observed peripartum. Additional studies addressing the relative contribution of cell surface bound UPA to net proteolysis of fetal membranes and decidua at labour may provide insight into the biochemical mechanisms that operate during normal and pre-term delivery.

The work described in this manuscript was supported by a grant from the National Health and Medical Research Council of Australia (G. E. Rice and M. S. Baker) and the 3AW Community Services Trust (G. E. Rice). G. E. Rice is in receipt of a National Health and Medical Research Council of Australia Senior Research Fellowship. The authors gratefully acknowledge the assistance of clinical research midwives Debra Rushford and Madonna Grehan for collection of human gestational tissues. The monoclonal antibody against human MMP-9 was kindly provided by M. K. Bodden, University of Alabama at Birmingham, Birmingham, Alabama, USA.

\section{References}

Blasi F (1993) Urokinase and urokinase receptor - a paracrine autocrine system regulating cell migration and invasiveness Bioessays 15 105-111

Bryant-Greenwood GD and Yamamoto SY (1995) Control of peripartal collagenolysis in the human chorion-decidua American Journal of Obstetrics and Gynecology 172 63-70

Burgos H, Hsi BL, Yeh CJG and Faulk WP (1982) Plasminogen binding by human amniochorion. A possible factor in premature rupture of membranes American journal of Obstetrics and Gynecology 143 958-963

Conese M and Blasi F (1995) Urokinase/urokinase receptor system: internalisation/degradation of urokinase-serpin complexes: mechanism and regulation Biological Chemistry Hoppe Seyler 376 143-155

Ellis V and Dano K (1991) Plasminogen activation by receptor-bound urokinase Seminars in Thrombosis and Hemostasis 17 194-200

Emonard H and Grimaud JA (1990) Matrix metalloproteases. A review Cellular and Molecular Biology 36 131-153

Granstrom LM, Ekman GE, Malmstrom A, Ulmsten U and Woessner JF, Jr (1992) Serum collagenase levels in relation to the state of the human cervix during pregnancy and labor American Journal of Obstetrics and Gynecology $1671284-1288$

Heussen C and Dowdle EB (1980) Electrophoretic analysis of plasminogen activators in polyacrylamide gels containing sodium dodecyl sulfate and copolymerised substrates Analytical Biochemistry 102 196-202

Ibrahim MEA, Bou-Resli MN, Al-Zaid NS and Bishay LF (1983) Intact fetal membranes. Morphological predisposal to rupture Acta Obstetricia et Gynecologica Scandinavica 62 481-485

Jeffrey JJ (1991) Collagen and collagenase: pregnancy and parturition Seminars in Perinatology 15 118-126

Jenkins DM, O'Neill M, Mattar M, France VM, Hsi BL and Faulk WP (1983) Degenerative changes and detection of plasminogen in fetal membranes that rupture prematurely British Journal of Obstetrics and Gynaecology 90 841-846

Lei H, Vadillo-Ortega F, Paavola LG and Strauss JFI (1995) 92-kDa gelatinase (matrix metalloproteinase-9) is induced in rat amnion immediately prior to parturition Biology of Reproduction 53 339-344

Plow E, Herren T, Redlitz A, Miles LA and Hoover-Plow JL (1995) The cell biology of the plasminogen system FASEB Journal 9 939-945

Rajabi MR, Dean DD, Beydoun SN and Woessner JF, Jr (1988) Elevated tissue levels of collagenase during dilation of the uterine cervix in human parturition American Journal of Obstetrics and Gynecology 159 971-976

Ries C and Petrides PE (1995) Cytokine regulation of matrix metalloprotease activity and its regulatory dysfunction in disease Biological Chemistry Hoppe Seyler 376 345-355

Salamonsen LA (1996) Matrix metalloproteinases and their tissue inhibitors in endocrinology Trends in Endocrinology and Metabolism 728-34

Schmitt M, Wilhelm O, Janicke F, Magdolen V, Reuning U, Ohi H, Moniwa H, Kobayashi H, Weidle $\mathbf{U}$ and Graeff $\mathbf{H}$ (1995) Urokinase-type plasminogen activator (UPA) and its receptor (CD87): a new target in tumour invasion and metastasis Journal of Obstetrics and Gynaecology 21 $151-165$ 
Shimonovitz S, Hurwitz A, Dushnik M, Anteby E, Geva-Eldar T and Yagel S (1994) Developmental regulation of the expression of 72 and $92 \mathrm{kd}$ type IV collagenases in human trophoblast: a possible mechanism for control of trophoblast invasion American Journal of Obstetrics and Gynecology 171 832-838

Tsatas D, Baker MS and Rice GE (1997) Tissue-specific expression of the relaxed conformation of plasminogen activator inhibitor-2 and low density lipoprotein receptor-related protein in human term gestational tissues Journal of Histochemistry and Cytochemistry 45 1593-1602

Tsatas D, Baker MS, Moses EK and Rice GE (1998) Gene expression of plasminogen activation cascade components in human term gestational tissues with labour onset Molecular Human Reproduction 4 101-106
Vadillo-Ortega F, Gonzalez-Avila G, Furth EE, Lei H, Muschel RJ, StetlerStevenson WG and Strauss JFI (1995) 92-kd type IV collagenase (matrix metalloprotease-9) activity in human amniochorion increases with labour American Journal of Pathology 146 148-156

Vassalli JD, Sappino AP and Belin D (1991) The plasminogen activator/ plasmin system Journal of Clinical Investigation 88 1067-1072

Watanabe T, Araki M, Mimuro J, Tamada T and Sakata Y (1993) Fibrinolytic components in fetal membranes and amniotic fluid American Journal of Obstetrics and Gynecology 168 1283-1289

Woessner JF, Jr (1991) Matrix metalloproteinases and their inhibitors in connective tissue remodelling FASEB Journal 5 2145-2154 